\title{
Mifepristone and misoprostol versus misoprostol alone in management of late intrauterine fetal death
}

\section{Shilpa Gupta*, Bhumika Kagathra, Ajesh Desai}

Department of Obstetrics and Gynaecology, GMERS Medical College, Sola, Ahmedabad, Gujarat, India

Received: 07 August 2016

Revised: 12 August 2016

Accepted: 16 August 2016

\section{*Correspondence:}

Dr. Shilpa Gupta,

E-mail: shilp7anup@gmail.com

Copyright: () the author(s), publisher and licensee Medip Academy. This is an open-access article distributed under the terms of the Creative Commons Attribution Non-Commercial License, which permits unrestricted non-commercial use, distribution, and reproduction in any medium, provided the original work is properly cited.

\section{ABSTRACT}

Background: The objective was to assess the efficacy and safety of pretreatment with Mifepristone in induction of late intrauterine fetal death in combination with misoprostol.

Methods: A prospective study was carried out in GMERS Medical College, Sola, Ahmedabad between October 2014 to April 2016. Data from 72 women with intrauterine fetal death between the gestational age of 24 to 42 weeks were analyzed. Group A women received single oral dose of $200 \mathrm{mg}$ Mifepristone followed 36 to 48 hours later with Misoprostol (200-50 microgram) every 4 hour to a maximum of 5 doses. The first dose was kept vaginally in the posterior fornix and the rest were given orally. The dose of Misoprostol depended upon the gestational age and the parity. Group B women received only Misoprostol. If the first cycle failed, then after a break of 24 hour, a second course of Misoprostol was started. Outcomes were measured in terms of induction to delivery interval and number of Misoprostol doses needed.

Results: Maternal age, parity, gestational age and pre-induction bishop score were comparable in both the groups. Induction to delivery interval was shorter in the combination regimen. Total dose of Misoprostol needed was also less in the Group pretreated with Mifepristone. In group A 93.3\% women delivered within 24 hours of first dose of misoprostol while in group B it was $80.5 \%$. More women in group B required oxytocin. Regarding the complications during labor and delivery the two groups did not have major differences.

Conclusions: Both regimens are safe for the induction of labour in late IUFD. However, the induction delivery interval and the dose of misoprostol needed was decreased by the pretreatment with Mifepristone.

Keywords: Late intrauterine fetal death, Mifepristone, Misoprostol, Induction of labour

\section{INTRODUCTION}

In order to achieve the fruit of motherhood, each and every woman has to go through the journey of labour pain which is often compared to the pain of many bones breaking simultaneously. But in those unfortunate women with intrauterine fetal death, the picture is different. Here the woman has to suffer but there is no baby to take home. In such cases, quick delivery of the fetus is usually requested by the relatives without any medical reason for it. Therefore, a better method which cut shorts the induction delivery interval has to be relied upon. ${ }^{1}$

Since decades, prostaglandins are being used for induction of labour in intrauterine fetal death cases.,3 Misoprostol, a prostaglandin E1 analogue, is the extensively studied and the most preferred choice due to its ease of administration, low cost and stability at room temperature. ${ }^{1}$ However, repeated doses has its side effects. 
Mifepristone, antagonize the action of progesterone at the receptor level and has a accepted role in the first and second trimester termination of pregnancy. ${ }^{4,5}$ Mifepristone, if administered before Misoprostol has been shown to increase the sensitivity of the uterus to prostaglandins and ripens the cervix. Thus lower doses of misoprostol are required and hence the associated side effects and the induction delivery interval are curtailed in those unfortunate women with IUFD which is of utmost importance.

The aim of our study was to assess the efficacy, safety and tolerance of the combination regimen of Mifepristone and Misoprostol in comparison to the conventional use of Misoprostol alone, so as to find a better management option.

\section{METHODS}

This prospective study included 72 women with intrauterine fetal death after 24 weeks of gestation. The study was carried out in the Department of Obstetrics and Gynaecology, GMERS Medical College, Sola, Ahmedabad, in the time period of October 2014 to April 2016.

\section{Exclusion criteria was,}

1) Women in labour on admission

2) With previous LSCS or any other scar on uterus.

3) Any other obstetrical or medical indication for immediate delivery

All other eligible women were included in the study after taking informed consent.

Period of gestation was calculated by the last menstrual period. Ultrasonography was used to know the gestational age in those who did not remember LMP. The diagnosis of IUFD was confirmed through USG by the absence of fetal cardiac pulsation. A detailed history, physical and obstetrical examination and all routine baseline investigation was done on admission according to our hospital protocol. Assessment of cervix was based on bishop scoring. ${ }^{10}$

Data from 72 women with IUFD were analyzed. Group A included 38 women who were given Mifepristone $200 \mathrm{mg}$ orally. After 36 to 48 hours interval, they were given Misoprostol which was repeated every 4 hour for a maximum of 5 doses. The first dose was kept vaginally in the posterior fornix and the subsequent doses were given orally. The dose of Misoprostol was adjusted according to the gestational age.

For women with 1) 24 to 28 weeks gestation, the dose was 200 microgram, 2) 28 to 34 weeks, the dose was 100 microgram, 3) 34 weeks onwards, the dose was 50 microgram.
Group B patients, which included 36 women, were only given Misoprostol dose schedule. If the first course was not successful, then a second course of Misoprostol was repeated after 24 hours. After Misoprostol administration, pulse, blood pressure, temperature, uterine contraction and systemic symptoms were monitored. In case of any side effects, further appropriate treatment was given as per the concerned physician advice in either group. Oxytocin was used to augment the active stage of labor if needed.

Expelled fetus and placenta were examined clinically to confirm complete uterine evacuation. If in doubt, ultrasonography was performed. Number of doses of Misoprostol used and induction to delivery interval were noted. Successful induction was defined as delivery within 24 hours of first dose of misoprostol.

Statistical analysis was performed using SPSS software version 20. Chi Square test and fisher exact test were used for statistical analysis. Differences were considered statistically significant if $\mathrm{P}<0.05$.

\section{RESULTS}

In our study 72 women with IUFD were analyzed (36 in group A and 36 in group B). 6 women in group A delivered with mifipristone alone, so only 30 women required misoprostol and were compared with group B.

As regards to the obstetrical parameters of maternal age, gestational age, parity and pre induction bishop score, both the groups were comparable with no significant difference (Table 1).

Table 1: demographic profile and obstetric parameters.

\begin{tabular}{|llll|}
\hline & $\begin{array}{l}\text { Group A } \\
(\mathbf{n}=30)\end{array}$ & $\begin{array}{l}\text { Group B } \\
(\mathbf{n}=36)\end{array}$ & $\begin{array}{l}\text { P } \\
\text { value }\end{array}$ \\
\hline Age (years) & $28.4 \pm 5.4$ & $27.5 \pm 4.5$ & 0.4 \\
\hline $\begin{array}{l}\text { Gestational age } \\
\text { (weeks) }\end{array}$ & $32.4 \pm 6.4$ & $31.2 \pm 6.2$ & 0.44 \\
\hline Parity & $2.2 \pm 1.6$ & $2.6 \pm 1.4$ & 0.28 \\
\hline Bishop score & $3 \pm 1.6$ & $2.6 \pm 1.8$ & 0.3 \\
\hline
\end{tabular}

The efficacy of combination regimen was compared by the following parameter.

Table 2: comparison of efficacy of both the regimens.

\begin{tabular}{|llll|}
\hline & $\begin{array}{l}\text { Group A } \\
(\mathbf{n = 3 0})\end{array}$ & $\begin{array}{l}\text { Group B } \\
(\mathbf{n}=\mathbf{3 6})\end{array}$ & $\begin{array}{l}\text { P } \\
\text { value }\end{array}$ \\
\hline $\begin{array}{l}\text { No of dosage of } \\
\text { misoprostol }\end{array}$ & $2.9 \pm 1.2$ & $4.2 \pm 1.3$ & 0.001 \\
needed & $9.6 \pm 3.03$ & $16.2 \pm 6.2$ & 0.001 \\
\hline $\begin{array}{l}\text { Induction to } \\
\text { delivery interval } \\
\text { (hours) }\end{array}$ & & & \\
\hline
\end{tabular}


The number of dosage of misoprostol required in both the groups were compared and was found to be significantly less in women pretreated with mifepristone (group A). Minimum and maximum dosage required was same in both groups. Mean dose given was 2.9 in group A.

Induction to delivery interval was calculated from the first dosage of misoprostol administered to the expulsion of fetus. Mean induction to delivery interval in group A and group B was 9.6 and 16.2 hours respectively, which was significantly less in group pretreated with mifepristone. In group A, 93.3\% women delivered within 24 hours of first dosage of misoprostol, while it was $80.5 \%$ in group B.

Table 3: Outcome after induction.

\begin{tabular}{|lll|}
\hline Study parameters & $\begin{array}{l}\text { Group A } \\
(\mathbf{n = 3 0})(\%)\end{array}$ & $\begin{array}{l}\text { Group B } \\
(\mathbf{n}=36)(\%)\end{array}$ \\
\hline Adverse effects & $3(10.0 \%)$ & $6(16.7 \%)$ \\
\hline Oxytocin required & $2(6.6 \%)$ & $7(19.4 \%)$ \\
\hline Analgesia required & $4(13.3 \%)$ & $9(25.0 \%)$ \\
\hline Retain placenta & $0(0 \%)$ & $1(2.7 \%)$ \\
\hline $\begin{array}{l}\text { Second cycle of } \\
\text { misoprostol }\end{array}$ & $2(6.6 \%)$ & $7(19.4 \%)$ \\
\hline
\end{tabular}

Adverse effects such as nausea, vomiting, diarrhea and hyperthermia were recorded. The tolerance of combination regimen was good. No cases of uterine hypertonicity, tachysystole, hemorrhage or coagulopathy were recorded in any group. Augmentation with oxytocin was required in $6.6 \%$ of group A women in comparison to $19.4 \%$ in group B. Data on analgesic use were also recorded. Oral analgesic was given in $13.3 \%$ and $25.0 \%$ of group A and group B women respectively.

\section{DISCUSSION}

The combination regimen of mifepristone and misoprostol is well established in the management of early first trimester termination of pregnancy. $(5,6)$ This study has demonstrated the same effectiveness in late intrauterine fetal death cases. Dosage of misoprostol used varied in different studies. We had used the dose regimen based on our experience of using mifepristone and misoprostol in the context of termination of pregnancy and miscarriage.

Wagaarachchi et al, in their study concluded that combination regimen was safe and more effective in comparison to misoprostol alone. ${ }^{7}$ Fairley et al had a similar experience in their study. ${ }^{8}$

In our study, induction to delivery interval was less in group pretreated with mifipristone. Our study is in agreement with the study of Vayrymen et al, and Sharma et al. ${ }^{11,12}$ Induction to delivery interval was shortest (7 hours) in study of Fairley et al, while it was maximum (12.8 hours) in study of Vayrymen et al. ${ }^{8,11}$ In our study it was 9.8 hours in combination regimen.
Dosage of misoprostol required was significantly less in the mifipristone group which can be explained due to its pharmacodynamics as mentioned earlier.

In the study by Waggarachchi et al, $87.5 \%$ of women of combination regimen delivered within 24 hours. $^{7}$ In present study, 93.3\% women pretreated with mifipristone had successful induction. In study by Vayrymen et al successful induction rate was $73 \%$ as it used only 25 micrograms misoprostol. ${ }^{11}$

In our study gastrointestinal side effects were noticed in $16.7 \%$ of oral misoprostol group women. Similar result was seen in study of Fairley et al $(15 \%){ }^{8}$

Oral analgesia was required more in the misoprostol only group, which may be explained due to the prolonged duration of labor. However, there is a probability of confounding factor of patient's perception of pain.

As per our hospital protocol, in our study, we kept all the patients admitted after mifipristone administration for observation, but no adverse effects were noticed. However 6 patients delivered with mifipristone administration only after 30-36 hours.

So patients could be sent to home after mifipristone administration with proper counseling and return back after 48 hours for misoprostol when monitoring is required. This will reduce the hospital cost.

\section{CONCLUSION}

In order to cut short the fruitless journey of labor pain in IUFD cases, pretreatment with mifipristone is more effective as it shortens the duration of labor without any increase in adverse effect. It is equally safe, more effective and easily tolerable when compared to misoprostol only and thus should be considered by the obstetricians in intrauterine fetal death cases. However, conventional regimen with misoprostol alone may be appropriate in settings where cost is a prohibitive factor.

\section{Funding: No funding sources \\ Conflict of interest: None declared}

Ethical approval: The study was approved by the Institutional Ethics Committee

\section{REFERENCES}

1. Ngai SW, Tang OS, Ho PC. Prostaglandins for induction of second-trimester termination and intrauterine death. Best Pract Res Clin Obstet Gynecol. 2003;17(5):765-75.

2. Fletcher HM, Wharfe G, Simeon D, Mitchell S, Brown D. Induction of labor with intravaginal misoprostol versus dinoprostone in intrauterine death: a retrospective study. J Obstet Gynaecol. 1996;16:155-8. 
3. Bugalho A, Bique C, Machungo F, Faaundes A. Induction of labour with intravaginal misoprostol in intrauterine fetal death. Am J Obstet Gynaecol 1994;171:538-41.

4. Newhall EP, Winikof B. Abortion with mifepristone and misoprostol: regimens, efficacy, acceptability and future directions. Am J Obstet Gynecol 2000;182:44-53.

5. Ashok PW, Flett GM, Templeton A. Effective, lowcost regimens for medical termination of pregnancy at all gestations. Contemp Rev Obstet Gynecol. 1999:11:207-12.

6. Ashok PW, Penney GC, Flett GM, Templeton A. An effective regimen for early medical abortion: a report of 2000 consecutive cases. Hum Reprod. 1998;13(10):2962-5.

7. Wagaarachchi PT, Ashok PW, Narvekar NN, Smith NC, Templeton A. Medical management of late intrauterine death using a combination of mifepristone and misoprostol. BJOG. 2002;109(4):443-7.
8. Fairley TE, Mackenzie M, Owen P, Mackenzie F. Management of late intrauterine death using a combination of mifepristone and misoprostolexperience of two regimens. Eur J Obstet Gynecol Reprod Biol. 2005;118(1):28-31.

9. Royal College of obstetricians and gynaecologists (RCOG). Late intrauterine fetal death and stillbirth. London (UK): Royal College of Obstetricians and Gynaecologists (RCOG) (Green-top guideline; no. 55); 2010:33

10. Bishop EH. Pelvic scoring for elective induction. Obstet Gynecol. 1964:24:266-8.

11. Vayrynen W, Heikinheimo O, Nuutila $M$. Misoprostol-only versus mifepristone plus misoprostol in induction of labor following intrauterine fetal death. Acta Obstetricia et Gynaecologica Scandinavica. 2007;86:701-5.

12. Sharma D, Singhal SR, Poonam Paul A, Tai K. J Obstet Gynaecol. 2011;50:332-5.

Cite this article as: Gupta S, Kagathra B, Desai A. Mifepristone and misoprostol versus misoprostol alone in management of late intrauterine fetal death. Int J Reprod Contracept Obstet Gynecol 2016;5: 2935-8. 